\title{
Left Atrial Roof Incision for Mitral Valve Interventions and Left Atrial Mass Resection: A Safe Alternative for Excellent Exposure. A Single Center Experience
}

\author{
Ahmed Ahmed, MD, Mohammed Abd Al Jawad, MD \\ Department of Cardiothoracic Surgery, Ain Shams University, Cairo, Egypt
}

\section{ABSTRACT}

Background: Proper visualization has always been the cornerstone for conducting proper cardiac interventions. Although many incisions have been described for mitral valve exposure, the feasibility of some comes at the expense of proper exposure. When it comes to a small left atrium, larger incisions may venture into critically situated structures, creating a heavy toll of increased morbidity and mortality. We aim to evaluate the safety and efficacy of a superior left atrium approach for mitral valve interventions and left atrial mass resection, particularly in a small left atrium.

Methods: We present our experience and early results as a retrospective study conducted at Cardiothoracic Surgery Department, Ain-Shams University, Cairo, Egypt. A total of 85 patients underwent mitral valve interventions and left atrial mass resection through limited incision in the left atrial dome.

Results: The study included 29 female patients and 56 male patients with a mean age of $42.56 \pm 7.39$ years. Twentyseven patients were NYHA class I-II and 58 patients were class III-IV. Mean ejection fraction was $55.47 \pm 8.56$. Three patients had mitral valve repair, 67 patients had mitral valve replacement, and 15 patients had resection of left atrial myxomas. Preoperative atrial fibrillation was present in $27 \%$ of the patients. Two patients had new incidence of atrial fibrillation, one patient had new atrial flutter, and one patient had complete heart block, requiring a permanent pacemaker. No mortality occurred in the series, and three patients needed re-exploration for bleeding.

Conclusions: Limited left atrial roof incision provides a safe and feasible exposure for conducting mitral valve interventions and resection of left atrial masses, especially in cases with a small left atrium.

\section{INTRODUCTION}

Mitral valve diseases comprise the vast majority of leftsided heart diseases, whether due to degenerative, ischemic, rheumatic, or neoplastic etiology. All these pathologies require a proper and decent exposure to the mitral valve complex and left atrial chamber, including the mostly obscured

Received December 28, 2017; received in revised form March 29, 2018; accepted April 27, 2018.

Correspondence: Dr. Mobammed Nabil Mohammed Abd Al Fawad, MD, 34 Abd Al Aziz Fabmy st., Heliopolis, Cairo, Egypt 11351; +201111219461 (e-mail: mobammed_abdaljawad@med.asu.edu.eg). interatrial septum to allow for competent repair, replacement, or tumor excision.

Many incisions have been introduced for left atrial exposure, and some have become standard, such as the inferior approach. In this approach, an incision is made in the left atrium just behind and parallel to the interatrial groove, giving an adequate access to the mitral valve in most cases. The trans-septal approach provides better exposure, yet it carries the grave risk of dividing the artery to the sinoatrial node. Some incisions are widely recognized as difficult to close, such as the Bi-atrial (Dubost) incision, or damaging, like the extended superior roof incision. Both provide excellent exposure, but their associated technical difficulties makes surgeons reluctant to use them [Pezzella 1998].

The superior approach was first described by Meyer in 1965. Some authors suggested that this technique may offer inadequate exposure, and should not be used for repair procedures on the mitral valve. This criticism caused the incision to be infrequently utilized by many surgeons [Meyer 1965]. The approach was revisited in 2002 by Légaré and colleagues for the purpose of mitral valve repair [Légaré 2003]. It was revisited again in 2017 by Spadaccio and colleagues as a novel exposure for removal of left atrial myxoma that depended on minimally invasive techniques [Spadaccio 2017].

Table 1. Patients' Demographics and Characteristics

\begin{tabular}{lcc}
\hline & $\mathrm{N}=85$ & $\%$ \\
\hline Age (Mean \pm SD) & $42.56 \pm 7.39$ & \\
Sex & & \\
Female & 29 & 34.1 \\
Male & 56 & 65.9 \\
Diabetes mellitus & 9 & 10.6 \\
Preoperative renal impairment & 0 & 0 \\
NYHA class I-II & 27 & 31.8 \\
NYHA class III-IV & 58 & 68.2 \\
Preoperative AF & 23 & 27 \\
EF & $55.47 \pm 8.56$ & \\
LA diameter in cm & $4.5 \pm 0.675$ & \\
\hline
\end{tabular}

Values are shown in mean \pm standard deviation, and percentage. SD indicates standard deviation; AF, atrial fibrillation; LA, left atrium; NYHA, New York Heart Association; EF, ejection fraction. 


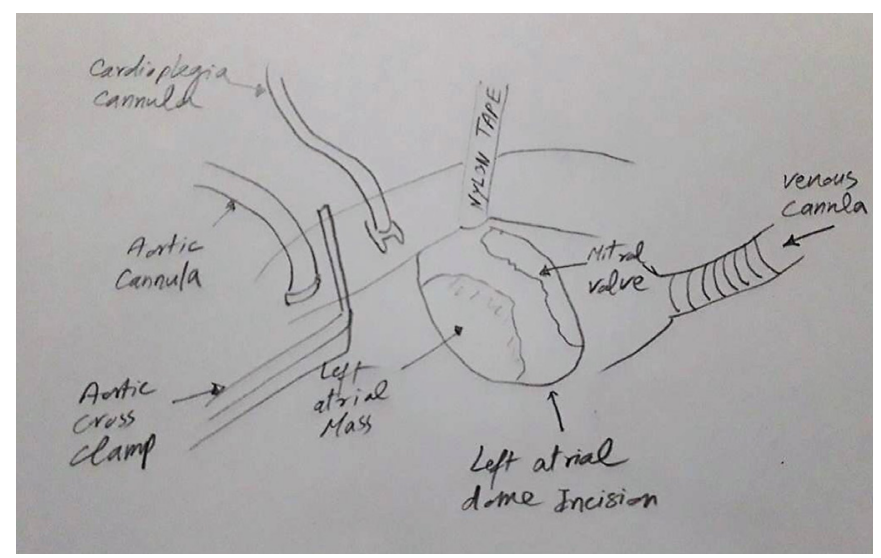

Figure 1. Left atrial dome incision.

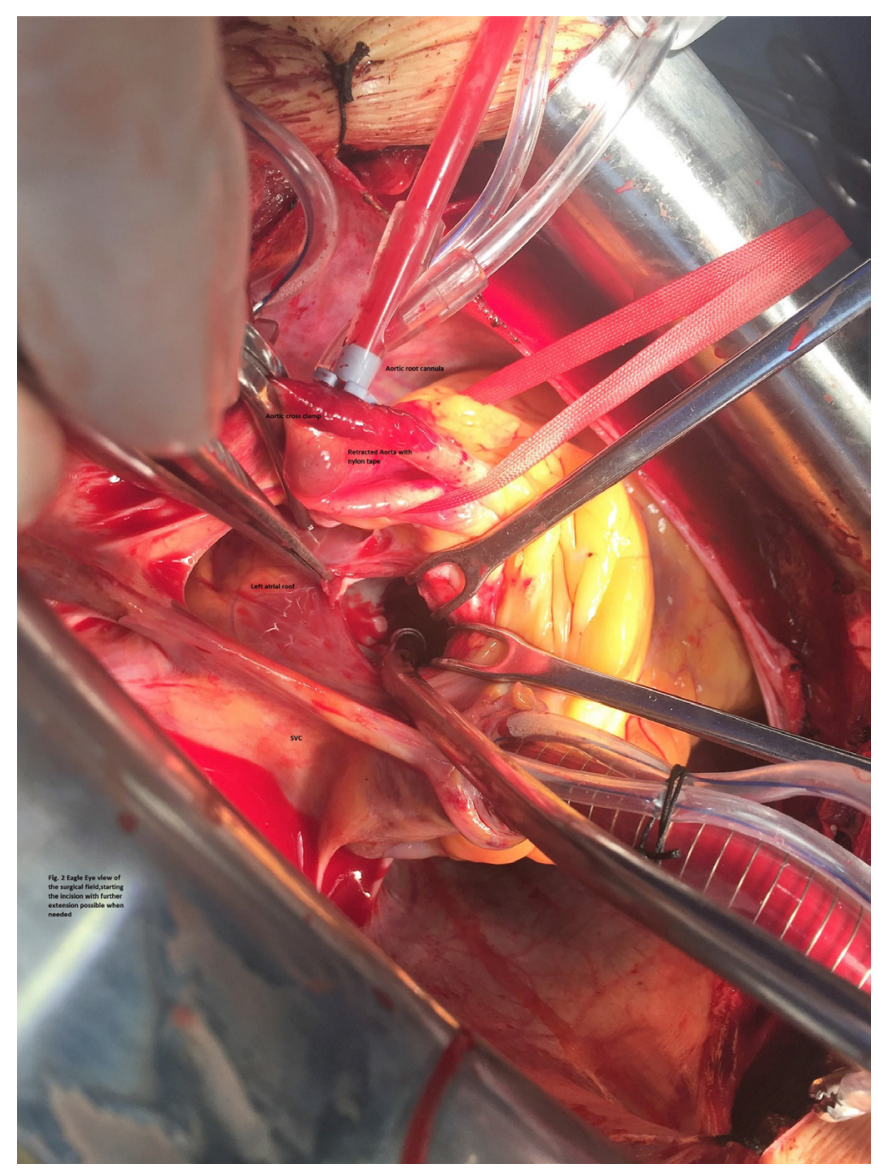

Figure 2. "Eagle eye" view of the surgical field, starting the incision with a further extension when needed.

At our institute, we deal with many mitral valve pathologies, mainly of rheumatic origin. In the past, patients were often referred late for surgery. This late referral led to larger left atrial dimensions, making visualization and surgery easy and comfortable. Currently, the earlier referral of these patients has led to operating upon smaller left atrial dimensions than before. In addition, operating on patients with
Table 2. Surgical Details

\begin{tabular}{lc}
\hline & $\%$ \\
Type of intervention & $\mathrm{N}=85$ \\
\hline MV repair & $3(3.5 \%)$ \\
MV Replacement & $67(78.9 \%)$ \\
Left atrial tumors & $15(17.6 \%)$ \\
Operation urgency & \\
$\quad$ Urgency & $26(30.6 \%)$ \\
$\quad$ Elective & $59(69.4 \%)$ \\
$\quad$ Emergency & $0(0.0 \%)$ \\
ACC time (minutes) & $61.78 \pm 16.43$ \\
Total bypass time (minutes) & $106.14 \pm 25.93$ \\
Post-operative ventilation (hours) & $16.32 \pm 5.12$ \\
Inotropic support & $40(47 \%)$ \\
ICU stay (hours) & $32.57 \pm 14.57$ \\
Total blood loss in mL & $398 \pm 312.5$ \\
\hline
\end{tabular}

Values are shown in numbers and percentage, mean \pm standard deviation MV indicates Mitral Valve; ACC, aortic cross clamp; ICU, intensive care unit.

ischemic mitral regurgitation or left atrial masses is associated with a "normal or relatively small" left atrium. This makes surgery less comfortable, and requires more exposure, and put our surgeons out of their comfort zone. This has mandated adoption of other incisions, including the "less favorable" trans-septal approach and the relatively new-to-ourinstitute left atrial dome incision.

We would like to share our experience of mitral valve interventions and left atrial mass resection through the dome of the left atrium.

\section{PATIENTS AND METHODS}

From January 2015 to September 2017, 85 patient of different pathologies- namely degenerative, ischemic, and rheumatic- underwent mitral valve interventions and left atrial myxomas resections through limited incision in the left atrial dome. All interventions were performed by the same surgical team. This study was carried out at the Cardiothoracic Surgery Department of Ain Shams University, Cairo, Egypt. The study underwent routine approval by the medical ethical committee of Ain Shams University.

The patients were prepped and draped in a supine position. General anesthesia and routine lines were carried out for preparation of open heart cases as usual. Transesophageal echocardiography was performed for proper evaluation of the mitral valve and cardiac function.

A standard median sternotomy was performed, and the pericardium was opened in an inverted $\mathrm{T}$ shaped manner. Heparin was given, and high aortic cannulation was performed. Bi-Caval cannulation was carried out, and an aortic 


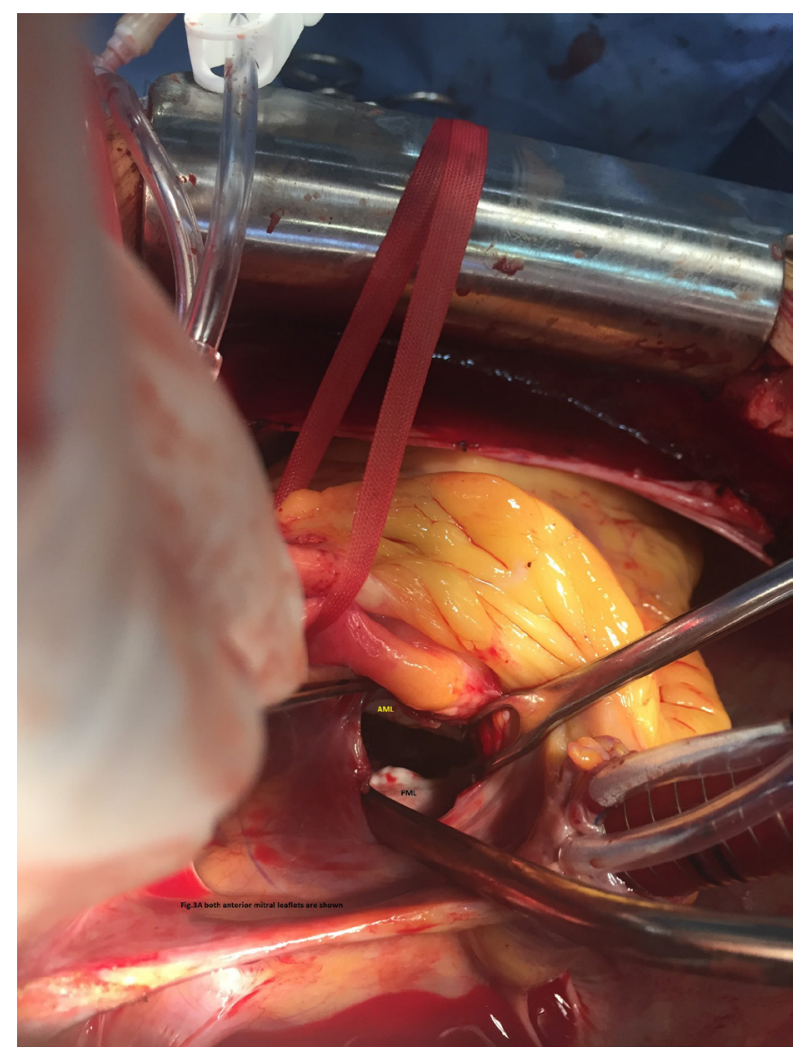

Figure 3a. Eye examination of the mitral valve; both anterior and mitral leaflets are shown. AML indicates anterior mitral leaflet; PML, posterior mitral leaflet.

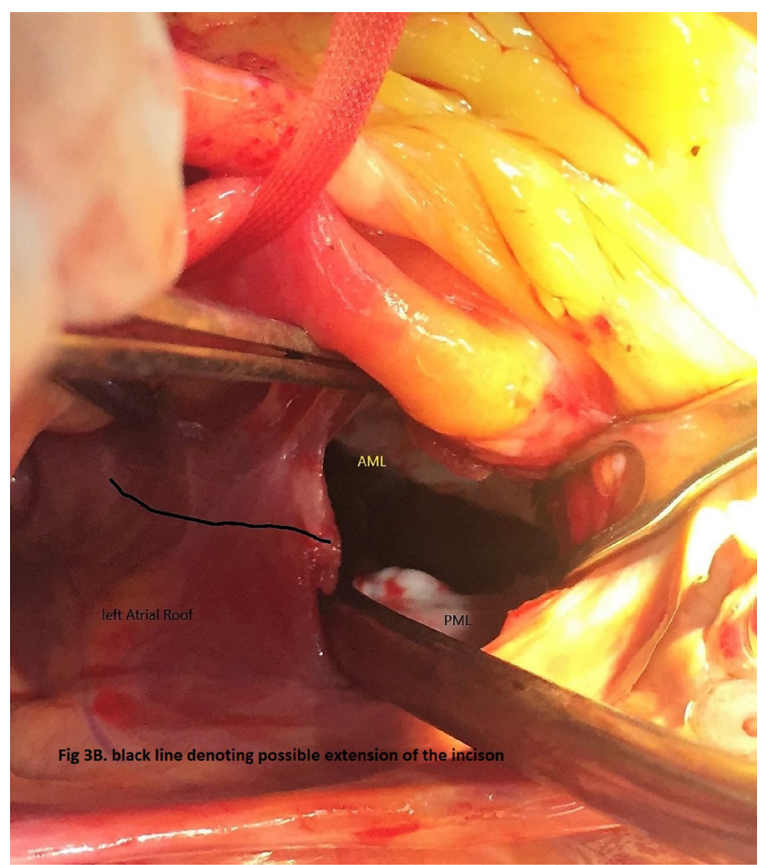

Figure 3b. Eye examination of the mitral valve, with black line denoting possible extension of the incision. AML indicates anterior mitral leaflet; PML, posterior mitral leaflet.

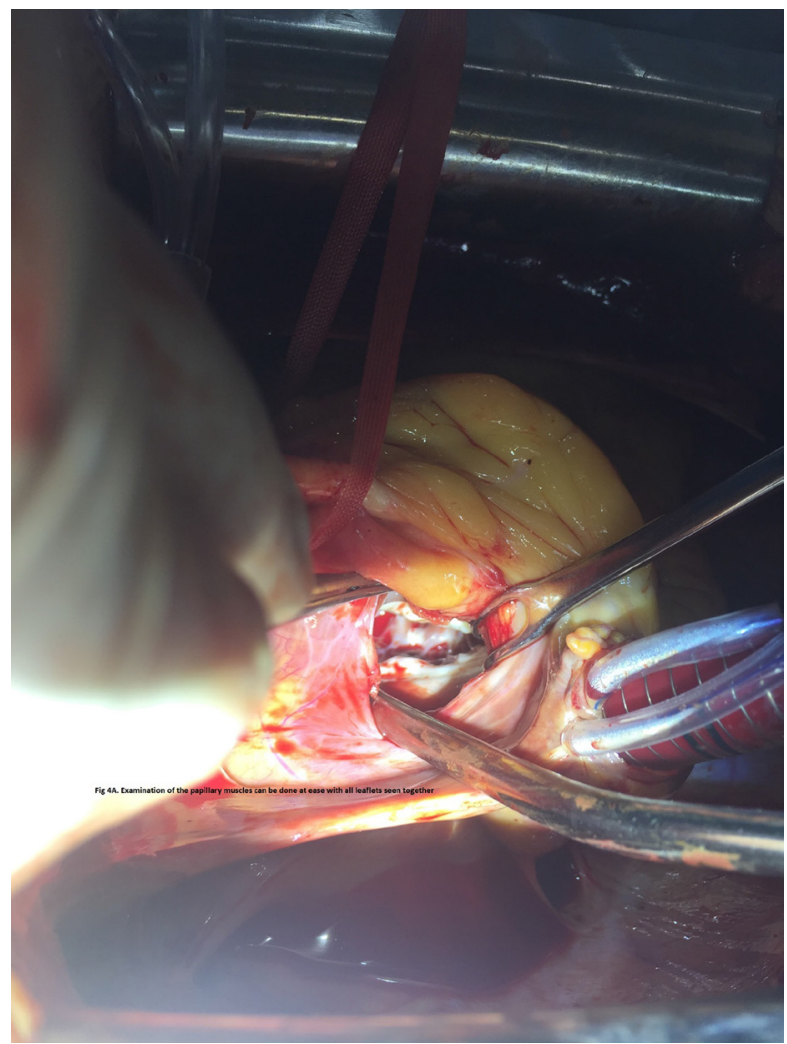

Figure 4a. Eye examination of the mitral valve. Examination of the papillary muscles can be done at ease, with all leaflets seen together.

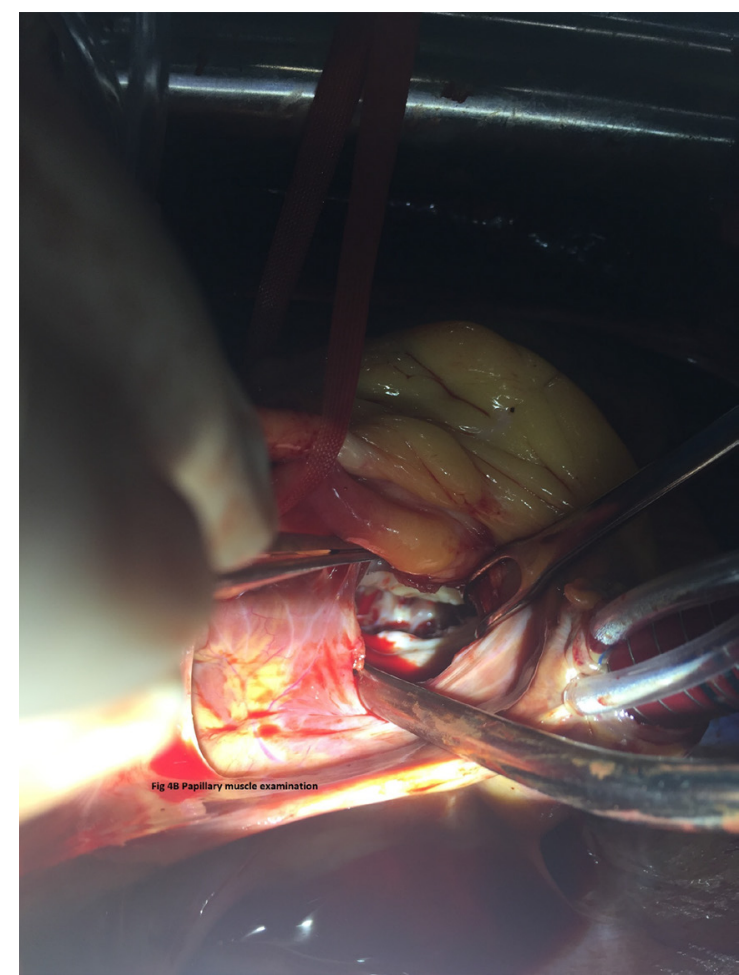

Figure 4b. Papillary muscle examination. 


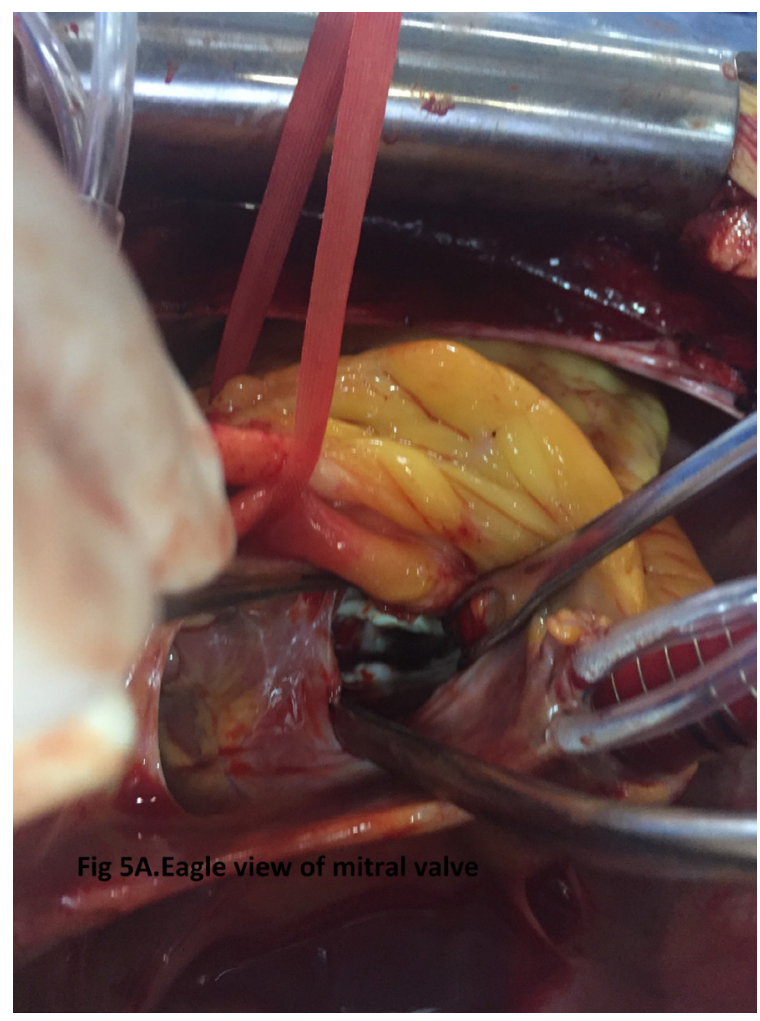

Figure 5a. Eye examination of the mitral valve; eagle view of the mitral valve.

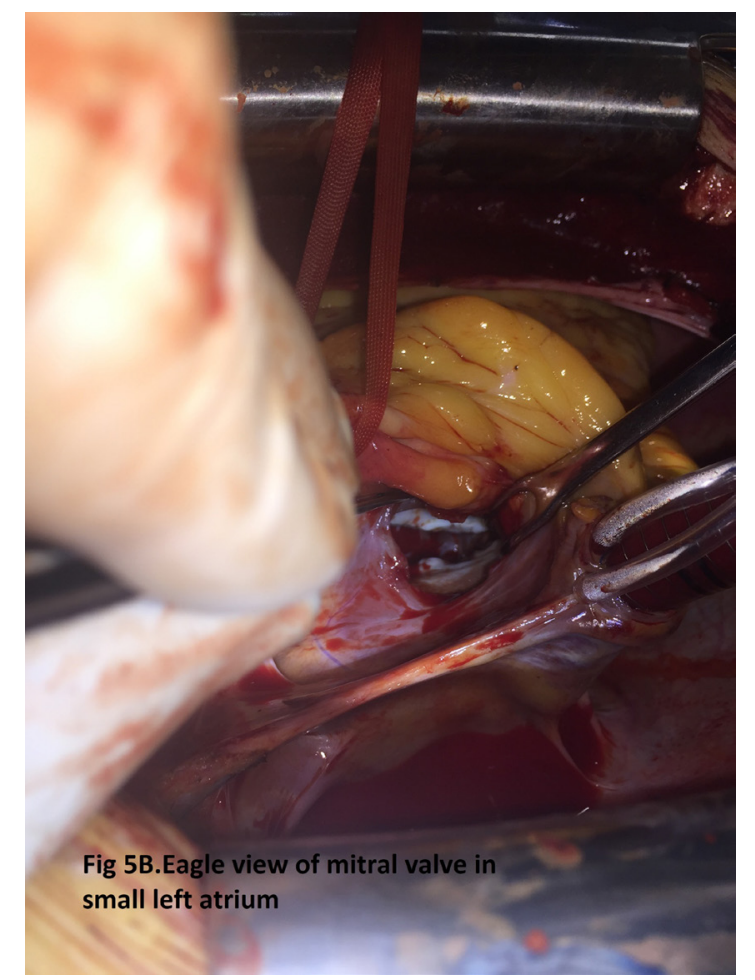

Figure 5b. Eye examination of the mitral valve; eagle view of mitral valve in small left atrium.

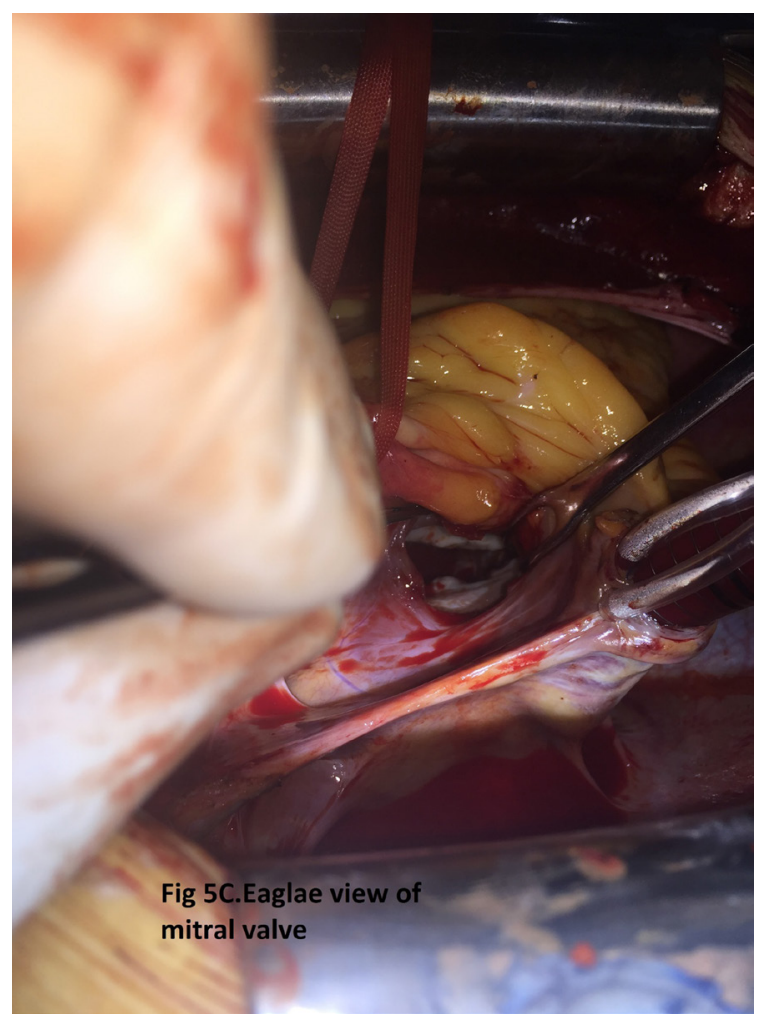

Figure $5 c$. Eagle view of the mitral valve.

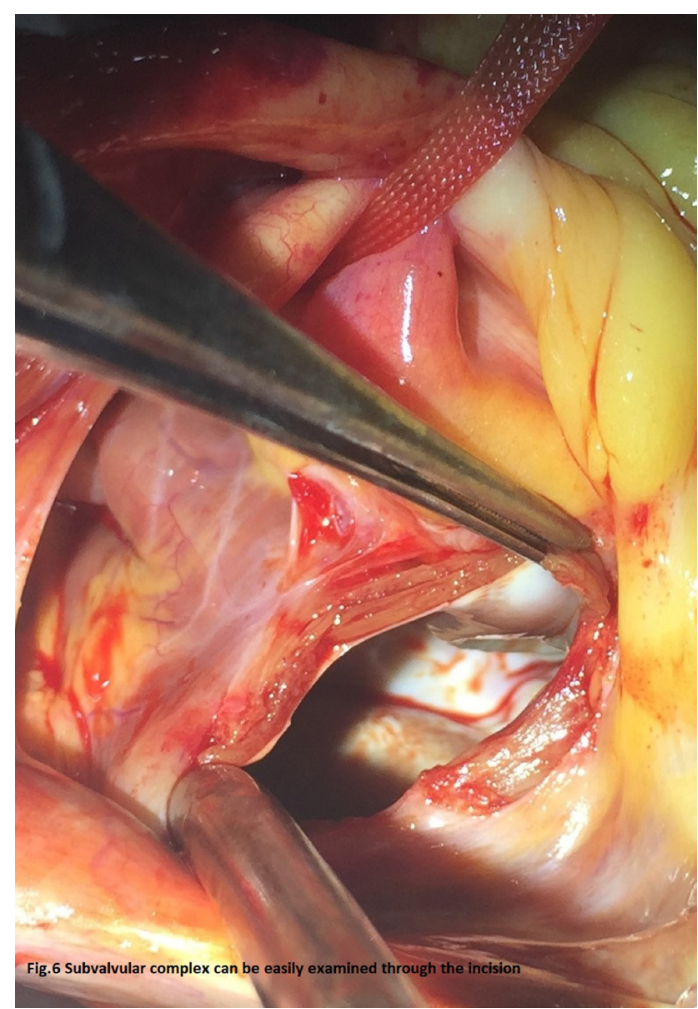

Figure 6. Eye examination of the mitral valve; subvalvular complex can be easily examined through the incision. 
Table 3. Post-Operative Complications

\begin{tabular}{lll}
\hline Complications & $\mathrm{N}=85$ & $\%$ \\
\hline Incidence of new AF & 2 & 2.3 \\
Incidence of new Flutter & 1 & 1.2 \\
Incidence of heart block & 1 & 1.2 \\
Post-operative cerebrovascular stroke & 1 & 1.2 \\
Mortality & 0 & 0.0 \\
Re-exploration of bleeding & 3 & 3.5 \\
Deep sternal wound infection & 2 & 2.3 \\
Post-operative renal impairment & 0 & 0.0 \\
Incidence of para valvular leak in replacement & 2 & $3 \%$ \\
patients (n=67) proved by intraoperative TEE & $(\mathrm{n}=67)$ & $(\mathrm{n}=67)$ \\
requiring reintervention at same session & & \\
\hline
\end{tabular}

Values are shown in numbers and percentages.

AF indicates atrial fibrillation.

root cardioplegia cannula was inserted in the ascending aorta. After adequate activated clotting time (ACT), cardiopulmonary bypass was commenced with moderate hypothermia $\left(28^{\circ} \mathrm{C}-32^{\circ} \mathrm{C}\right)$, the aorta was cross clamped, and intermittent cold anterograde blood enriched cardioplegia was given. A half dose of cardioplegia was repeated every 20 -minute interval as needed.

The ascending aorta was retracted gently towards the assistant to provide access to the left atrial roof. An initial incision was made in the roof of the left atrium, reaching the junction with the superior vena cava in the right side, and was directed towards the left superior pulmonary vein in the left side (Figures 1 and 2).

The original procedure was then carried out. Left atrial closure and deairing was done in standard routine fashion. Transesophageal echocardiography was performed once spontaneous circulation was resumed. All patients were transferred postoperatively to the ICU for monitoring and follow up.

\section{Statistical Analysis}

The results were expressed as numbers (mean values and standard deviation, median and range) and percentages as appropriate.

\section{RESULTS}

The patients' demographics included nine patients with confirmed diabetes mellitus preoperatively (10.6\%), 27 (31.8\%) patients with NYHA classification I-II, and 58 patients (68.2\%) with class III-IV. Preoperative atrial fibrillation occurred in 23 patients. The ejection fraction of the patients was $55.47 \pm 8.56$. Left atrial diameter ranged from 3.5 to $6.2 \mathrm{~cm}$, with a mean left atrial diameter of $4.5 \mathrm{~cm}$ (Table 1).

The majority of our patients $(78.9 \%)$ underwent mitral valve replacement due to the rheumatic nature of the mitral valve pathology. Elective cases accounted for 59 patients, and only 26 patients were operated on urgent basis. Of the 26 urgent patients, only one patient had preoperative infective endocarditis and vegetations over the mitral valve. Inotropic cardiac support was required for $47 \%$ of the patients (Table 2).

We encountered two new episodes of atrial fibrillation post operatively that failed to be reverted to normal sinus rhythm, one episode of new atrial flutter, and one episode of complete heart block requiring permanent pacemaker insertion. One patient suffered from a postoperative cerebrovascular stroke. In our series of patients, we had no mortalities. The postoperative total blood loss ranged from $150 \mathrm{ml}$ to $1400 \mathrm{ml}$, with a mean of $398 \mathrm{ml}$. Three patients needed re-exploration for bleeding not related to the atriotomy incision site in the immediate postoperative period. However, one patient developed a sternal wound infection that was improved with frequent dressing and intravenous antibiotics (Tables 2 and 3 ).

\section{DISCUSSION}

In 1965, Meyer was the first to describe this approach. Saksena et al, Molina, and Hirt et al favored the dome incision, describing it as "allowing adequate exposure of the mitral valve" [Hirt 1988; Molina 1988; Saksena 1971; Meyer 1965]. Larbalestier et al did not approve of this incision, describing it as being "not suitable for mitral valve repair" [Larbalestier 1992].

In 2003, Légaré and colleagues compared three common approaches of the mitral valve: the inter-atrial groove, the trans-atrial approach, and the dome of the left atrium. They showed that the dome approach can provide superior exposure, with good short-term and mid-term results in a wide variety of patients requiring mitral valve repair procedures [Légaré 2003].

In their published manuscript describing different approaches to the mitral valve, Pezella et al described the proper way to do this incision. They also demonstrated many pitfalls and technical errors associated with it. They showed how these pitfalls led to the incision being described as, allegedly, "inadequate". Following their steps, many authors now agree that this incision provides the "ultimate exposure," as it is directly perpendicular on the mitral valve annulus, giving both the surgeon and assistant an "eagle view" to the mitral valve apparatus [Pezzella 1998].

Recently, Spadaccio and colleagues published a case report of three patients with left atrial myxomas. They operated through a minimally invasive incision, using the dome of left atrium approach as a preferred incision for visualization of left atrial mass. They demonstrated excellent feasibility of mass excision and mitral valve inspection. They recommended this incision for redo mitral valve intervention, and/or left atrial tumors of benign origin through minimally invasive techniques [Spadaccio 2017].

Some left atrial tumors may arise from atypical sites. This may cause surgical difficulty in excising them. This unfavorable scenario was reported by El-Hassan and colleagues in a primary pulmonary vein leiomyosarcoma presenting as a left atrial mass, in which they found it very difficult to excise through the left atrial groove incision and had to do another 
right atrial incision. In our case, we could achieve it through the roof of the left atrium in a single incision. This proved the dome incision as a valuable route for totally excising the tumor and examining the whole left atrial chamber [El-Hassan 2017].

From our experience, the incision provided an excellent "anatomic" view of the whole mitral valve complex (anterior, posterior leaflets, annulus and sub valvular apparatus), without encroachment of undue retraction. Our advice is to gently retract the ascending aorta for proper exposure. It is necessary to avoid excessive aortic retraction in order to minimize dislodgement of any debris, or improper instillation of cardioplegic solution due to iatrogenic aortic insufficiency. Since the left atrial roof tissue is more fragile, a smaller $4 / 0$ poly propylene suture is required to close the incision in a double layer manner. As we mentioned before, the avoidance of the extension of the incision to the left will keep us safe from injuring valuable anatomic structures.

\section{Limitations of the Study}

Since these data represent early results, a larger number of patients will be needed to conduct further in-depth studies to evaluate feasibility of this incision in different left atrial pathologies and interventions. The evaluation of the learning curve of different junior surgeons from a technical point of view is also needed.

\section{CONCLUSION}

The limited superior approach incision through the dome of the left atrium provides a superior exposure for different mitral valve interventions and left atrial mass resection, without damage to any vital structures, especially in the case of small left atrial dimensions.

\section{REFERENCES}

El-Hassan NB, Faragalla AA, Elfadil S, et al. 2017. Primary pulmonary vein leiomyosarcoma presenting as left atrial mass: A case report. JESCTS 25:109-13.

Hirt S, Frimpongboateng K, Borst H. 1988. The superior approach to the mitral valve - is it worthwhile? Eur J Cardiothorac Surg 2:364-71.

Larbalestier RI, Chard RB, Cohn LH. 1992. Optimal approach to the mitral valve: Dissection of the interatrial groove. Ann Thorac Surg 54:1186-8.

Légaré JF, Buth KJ, Arora RC, et al. 2003. The dome of the left atrium: an alternative approach for mitral valve repair. Eur J Cardiothorac Surg 23:272-6.

Meyer BW, Verska JJ, Lindesmith GG, et al. 1965. Open repair of mitral valve lesions: the superior approach. Ann Thorac Surg 1:453-7.

Molina JE. 1988. The superior approach for mitral valve replacement. J Thorac Cardiovasc Surg 3:203-13.

Pezzella AT, Utley JR, Salm TJ. 1998. Operative approaches to the left atrium and mitral valve: an update. Oper Tech Thorac Cardiovasc Surg 3:74-94.

Saksena DS, Tucker BL, Lindersmith GG, et al. 1971. The superior approach to the mitral valve. Ann Thorac Surg 12:146.

Spadaccio C, Elkasrawy K, Sutherland FWH. 2017. New minimally invasive surgical approach for excision of left atrial myxoma. Gen Thorac Cardiovasc Surg 65:605-8. 